\title{
Treatment strategies to fight the new coronavirus SARS-CoV-2: A challenge for a Rubik's Cube solver
}

\author{
ELIZA TSITOURA $^{1}$, ELENI BIBAKI $^{1}$, MARIA BOLAKI $^{1}$, EIRINI VASARMIDI $^{1}$, ATHINA TRACHALAKI $^{2}$, \\ EMMANOUIL K. SYMVOULAKIS ${ }^{3}$, DEMETRIOS A. SPANDIDOS ${ }^{4}$ and KATERINA M. ANTONIOU ${ }^{1}$ \\ ${ }^{1}$ Department of Respiratory Medicine, University General Hospital of Heraklion, Laboratory of Molecular and \\ Cellular Pneumonology, Medical School, University of Crete, Heraklion, Crete, Greece; ${ }^{2}$ Interstitial Lung Disease \\ Unit Royal Brompton Hospital, London, UK; ${ }^{3}$ Clinic of Social and Family Medicine, Faculty of Medicine, \\ ${ }^{4}$ Laboratory of Clinical Virology, Medical School, University of Crete, Heraklion Crete, Greece
}

Received April 15, 2020; Accepted April 28, 2020

DOI: $10.3892 / \mathrm{etm} .2020 .8692$

\begin{abstract}
SARS-coronavirus-2 (SARS-CoV-2), the etiologic agent of the new lung disease COVID-19 is closely related to SARS-CoV, and together with MERS-CoV are three new human coronaviruses that emerged in the last 20 years. The COVID-19 outbreak is a rapidly evolving situation with higher transmissibility and infectivity compared with SARS and MERS. Clinical presentations range from asymptomatic or mild symptoms to severe illness. The prevalent cause of mortality is pneumonia that progresses to ARDS. The ongoing pandemic has already resulted in more than 135,000 deaths and an unprecedented burden on national health systems worldwide. Pending the availability of a vaccine, there is a critical need to identify effective treatments and a number of clinical trials have been implemented worldwide. Trials are based on repurposed drugs that are already approved for other infections, have acceptable safety profiles or have performed well in animal studies against the other two deadly coronaviruses. Supportive care remains the mainstay of therapy at present, as it is still unclear how well these data can be extrapolated to SARS-CoV-2. Most of those emerging re-introduced drugs are administered to patients in the context of clinical trials. In this review, we summarize the strategies currently employed in the treatment of COVID-19.
\end{abstract}

\section{Introduction}

On March 18, 2020, the World Health Organization launched the SOLIDARITY trial and soon after an add-on trial, a European

Correspondence to: Dr Katerina M. Antoniou, Department of Respiratory Medicine University General Hospital of Heraklion, Laboratory of Molecular and Cellular Pneumonology, Medical School, University of Crete, Heraklion, Crete, Greece

E-mail:kantoniou@med.uoc.gr

Key words: COVID-19, SARS-CoV-2, remdesivir, chloroquine, favipiravir, tocilizumab, stem cell therapy initiative of the Reacting consortium, the DISCOVERY trial was announced $(1,2)$. Currently, there are no approved therapies specific for any human $\mathrm{CoV}$. Trials are based on repurposed drugs that are already approved for other diseases, have acceptable safety profiles or have performed well in animal studies against the other two deadly coronaviruses, which cause SARS and Middle East respiratory syndrome (MERS). SOLIDARITY includes research looking at four possible therapeutics with direct antiviral actions: remdesivir, chloroquine and hydroxychloroquine, lopinavir plus ritonavir, and lopinavir plus ritonavir and interferon-beta while chloroquine will not be included in the DISCOVERY trial. Additionally, the DISCOVERY trial will include a placebo arm with standard of care while the SOLIDARITY trial will not be blinded and patients will know they received a treatment that would cause a placebo effect as stated by Ana Maria Henao Restrepo, a medical officer at the WHO Department of Immunization Vaccines and Biologicals. Additional information regarding lung imaging and blood gases will be monitored in the DISCOVERY trial besides data on hospitalization length and requirement for oxygen or ventilation to be collected by the SOLIDARITY trial (3).

SARS-coronavirus-2 (SARS-CoV-2), the etiologic agent of the new lung disease COVID-19 (4) is closely related to SARS-CoV, and together with MERS-CoV are three new human coronaviruses that emerged in the last 20 years (5). The three viruses are associated with increased risk of acute lung injury (6). As of April 15, 2020 more than 2 million people have been infected worldwide in 200 countries resulting in a death toll that surpasses 135,000 people in this ongoing pandemic (https:// www.worldometers.info/coronavirus/). SARS-CoV-2 is an enveloped, positive sense, single stranded, non-segmented RNA virus of the betacoronavirus family (7).

\section{Remdesivir}

Remdesivir targets virus replication, through inhibition of the viral RNA dependent RNA polymerase ( $\mathrm{RdRp})$ required for 
the copying and synthesis of novel viral genomes and viral mRNAs for the expression of viral proteins. Remdesivir incorporation in the nascent viral RNA by the RdRp results in premature chain termination and because of the high conservation of the core RdRp enzyme among coronaviruses. It has a broad-spectrum antiviral efficacy against multiple genetically distinct coronaviruses including the SARS-CoV and MERS-CoV in vitro and in vivo (8). Furthermore, it has shown prophylactic action against infection of corona viruses in animal models (8). Notably remdesivir potently blocked SARS-CoV-2 infection at low-micromolar concentration and showed high selectivity index in Vero E6 cells, a monkey epithelial cell line $\left(\mathrm{EC}_{50}=0.77 \mu \mathrm{M} ; \mathrm{CC}_{50}>100 \mu \mathrm{M}\right.$; SI >129.87) (9). It should be noted that remdesivir resistance is already documented for SARS-CoV and other coronaviruses that lead to reduced viral inhibition (10).

The outcomes in a cohort of patients hospitalized for severe COVID-19 who were treated with remdesivir on a compassionateuse basis were recently reported by Grein et al (11). Fifty-three patients received 10-day course of remdesivir, consisting of a loading dose of $200 \mathrm{mg}$ intravenously on day 1 , plus $100 \mathrm{mg}$ daily for the following 9 days. Improvement in oxygen-support status was observed in $68 \%$ of patients, and overall mortality was $13 \%$ over a median follow-up of 18 days although no data on viral dynamics were documented throughout the study. Clinical improvement was less frequent among patients receiving invasive ventilation than among those receiving noninvasive ventilation and among patients aged 70 years or older as compared with patients younger than 50 years.

\section{Chloroquine and hydroxychloroquine}

Chloroquine and hydroxychloroquine a less toxic derivative, represent potential broad-spectrum example of inhibiting viral cell entry. Chloroquine is a weak base that becomes entrapped in membrane-enclosed low $\mathrm{pH}$ organelles such as endosomes and lysosomes, and inhibits their acidification. Low $\mathrm{pH}$ in the endosomes regulates the action of proteases that lead to conformational changes of the virus envelope proteins allowing for the fusion of cellular and viral membranes and the escape of the viral genome into the cytosol. Attachment and entry of SARS-CoV-2 on host cells requires interaction of the spike protein subdomain 1 (S) with angiotensin converting enzyme 2 (ACE2) and its proteolytic cleavage by TMPRSS2 and to a lesser degree by the acid activated cathepsin B/L (12). Although the exact mechanism of SARS-CoV-2 entry is not completely understood and a new study has suggested that $\mathrm{pH}$-dependent fusion of viral and cellular membranes is dispensable for viral genome entry into host cells, chloroquine, similarly to remdesivir, inhibited SARS-CoV-2 infection at low-micromolar concentration and showed high selectivity index in Vero E6 cells $\left(\mathrm{EC}_{50}=1.13 \mu \mathrm{M}\right.$; $\left.\mathrm{CC}_{50}>100 \mu \mathrm{M}, \mathrm{SI}>88.50\right)(9)$.

Chloroquine is also used in the treatment of autoimmune diseases such as SLE and RA (13). Although the precise mechanism of action is not documented, inhibition of endosome acidification also interferes with innate immune response signaling from endosomal TLRs such as TLR 3, 7,8 and 9, that mainly detect nucleic acid PAMPS and DAMPS, and in this way reduce inflammatory responses. Therefore, chloroquine and hydroxychloroquine may also protect the host from overt inflammatory responses driven by the activation of immune cells such as macrophages by the increased load of viral RNA or cellular nucleic acids released from infected cells.

Results from clinical trials using chloroquine have provided promising results despite the limitations of these studies and suggest that chloroquine may represent a line of defense in the protection of medical stuff and patients with increased risk for severe COVID-19 symptoms. Chen et al (14), evaluated the efficacy of hydroxychloroquine (HCQ) in the treatment of 62 patients with mild COVID-19 from February 4 to 28, 2020 at Renmin Hospital of Wuhan University. Patients were randomized either in a control group, receiving standard treatment, or in the HCQ group in which the patients received standard treatment plus HCQ $200 \mathrm{mg} / \mathrm{bid}$ between days 1 and 5 . The study focused on time to clinical recovery (TTCR), clinical characteristics of patients and pulmonary recovery as it was depicted on chest CT results one day before (day 0 ) and one day after (day 6). A beneficial effect of HCQ in the treatment of COVID-19 was pointed out, despite the small number of the cases. More specifically, body temperature recovery time and cough remission time were significantly reduced in the HCQ treatment group. Moreover, the study of the chest CT scans revealed larger proportion of patients with improved pneumonia in the HCQ group (80.6\%), compared with the control group (54.8\%).

Gautret et al (15) from France conducted a single arm protocol from early March to March 16. Patients received $600 \mathrm{mg}$ of hydroxychloroquine daily. Azithromycin was added to the treatment regimen as the clinical presentation required and the control group was represented by untreated patients from another center and cases refusing the protocol. Patients' viral load in nasopharyngeal swabs was evaluated on daily basis. Virus clearance at day- 6 post-inclusion was the primary endpoint, while virus clearance during the study period, clinical parameters and occurrence of side-effects were considered secondary outcomes.

Regarding the effect of hydroxychloroquine on viral load, the study showed that a greater proportion of patients from the treated group had negative PCR results at days 3-6 postinclusion, compared with the control group. Interestingly, at day 6 post-inclusion, the percentage of negative PCR patients in the treated group was $70 \%$, while it was $12.5 \%$ in the control group ( $\mathrm{p}=0.001)$. The addition of azithromycin in the therapeutic regimen enhanced the beneficial effect of hydroxychloroquine more intensely. Patients treated with hydroxychloroquine and azithromycin were all (100\%) clear of virus at day 6 postinclusion, comparing with $57.1 \%$ in the group that was treated with hydroxychloroquine only and $12.5 \%$ in the control group $(\mathrm{p}<0.001)$.

\section{Kaletra}

The last two arms of SOLIDARITY and DISCOVERY trials include Kaletra which is a combination of two antiviral drugs - lopinavir and ritonavir - normally used to treat HIV. Lopinavir acts against the viral $3 \mathrm{CL}$ protease, responsible for the cleavage of the viral structural proteins from a polypeptide chain in order to produce new virions. Lopinavir has modest antiviral activity against MERS and is significantly less potent than remdesivir (16), however, in combination with ritonavir and the antiviral immunomodulator interferon $\beta$ it is currently in clinical trials for the treatment of MERS (17). The efficacy and safety of oral 
lopinavir-ritonavir for SARS-CoV-2 infection was tested through a randomized controlled trial in China, but found 'no benefit' beyond standard care (18). Kaletra with or without interferon $\beta 1$ will be tested in the SOLIDARITY and DISCOVERY trials.

\section{Favipiravir}

Favipiravir (brand name Avigan) is a type of RNA-dependent RNA polymerase (RdRp) inhibitor which acts through blocking the replication of RNA viruses and is a potential antiviral agent against SARS-CoV-2 (19). A prospective, multicenter, open-label, randomized superiority trial examined the efficacy of favipiravir $(n=120)$ versus arbidol $(n=120)$ for treating COVID-19 (20). There was no difference in the 7-day clinical recovery rate (primary endpoint) for favipiravir versus arbidol in the overall population $(61.21 \%$ versus $51.67 \%$; $\mathrm{p}=0.14)$. However, this difference existed for a subgroup of non-critical patients without hypertension or diabetes (favipiravir $71.43 \%$ versus arbidol 55.86\%, p=0.02) (20). Three registered clinical trials are planned regarding the use of favipiravir against COVID-19 (21-23).

Several promising theurapeutic options are emerging such as a protease inhibitor specific for TMPRSS2 cell protease required for virus entry (12), the broad spectrum orally bioavailable $\beta$-D-N4-hydroxycytidine (NHC, EIDD-1931) that is incorporated in the viral genome by the RdRp leading to the accumulation of deleterious mutations and viral inactivation (24).

\section{Tocilizumab (Actemra)}

The four current regimens in SOLIDARITY and DISCOVERY focus on antiviral drugs rather than treating ARDS symptoms that are actually the cause of the virus morbidity and mortality. Hyperinflammation in coronavirus disease 2019 (COVID-19) could be a driver of severity that may be managed with immunomodulatory therapeutic options $(25,26)$. Low-dose corticosteroid therapy ('shock-reversal'), over no corticosteroid therapy is suggested for adults with COVID-19 and refractory shock. In mechanically ventilated adults with COVID-19 and respiratory failure but without ARDS the routine use of systemic corticosteroids is not suggested. However, in mechanically ventilated adults with COVID-19 and ARDS using systemic corticosteroids is suggested (27-29). Importantly, the use of hydroxychloroquine, with or without the co-administration of azithromycin, may not be beneficial for the treatment of critically ill patients admitted to the ICU (30) and is not recommended (27,31).

Immunomodulatory drugs such as Tocilizumab (Actemra) 'anti-IL6' have been tested during the pandemic, however, great caution in inhibiting host antiviral responses should be taken (26). Tocilizumab (Actemra) is a recombinant humanized anti-human IL-6 receptor monoclonal antibody currently used for rheumatoid arthritis (32). Xu et al demonstrated that giving tocilizumab in addition to routine therapy to patients diagnosed as severe or critical COVID-19 is an effective treatment (33). COVACTA is a newly initiated randomized, double-blind, placebo-controlled phase III study to evaluate the safety and efficacy of intravenous Actemra/RoActemra added to standard care in adult patients hospitalized with severe COVID-19 pneumonia compared to placebo plus standard care. The primary and secondary endpoints include clinical status, mortality, mechanical ventilation and intensive care unit (ICU) variables (34).

\section{Stem cell therapy}

Finally, the use of stem cell therapy to treat COVID-19 is currently considered with multiple clinical trials from China registered at www.clinicaltrials.gov (35). In a recently published clinical trial with a limited number of patients, 7 patients ( 1 critically serious, 4 serious and 2 common) infected with the coronavirus received one dose of stem cell therapy with 3 patients in the control group ( 3 serious) did not. All patients with stem cell therapy recovered whereas in the control group, one patient died while another patient developed ARDS and only one patient in the control group was stable (36).

\section{Conclusion}

Important considerations in the successful testing and use of currently available and future therapies for COVID-19 are the timing of the treatment, the viral load of the patient and markers predictive of lung injury. Antiviral treatment is more efficient as a prophylactic measure and at earlier times during the infection, when virus replication is at its peak. Conversely, immunomodulatory and anti-inflammatory treatments may be more effective later and may be combined with careful monitoring of the patient viral loads.

The emergence of zoonotic human viruses causing pandemics are probably not going to be limited to the SARS-CoV-2 and represent enormous threats to global health. Pandemic preparedness in the future, broad-based vaccines and therapeutics, which are active against the higher risk virus families prone to emergence, are desperately needed, as well as global efforts to minimize their emergence.

\section{Acknowledgements}

Not applicable.

\section{Funding}

No funding was received.

\section{Availability of data and materials}

The information analyzed during the current study is available from the corresponding author on reasonable request.

\section{Authors' contributions}

All authors substantially contributed to the writing and revision of the work and read and approved the final manuscript.

\section{Ethics approval and consent to participate}

Not applicable.

\section{Patient consent for publication}

Not applicable. 


\section{Competing interests}

DAS is the Editor-in-Chief for the journal, but had no personal involvement in the reviewing process, or any influence in terms of adjudicating on the final decision, for this article. The other authors declare that they have no competing interests.

\section{References}

1. World Health Organization: Launch of SOLIDARITY trial (press release). Accessed March 18, 2020.

2. INSERM: Launch of a European clinical trial against COVID-19 (press release). Accessed March 22, 2020.

3. Kupferschmidt K and Cohen J: Race to find COVID-19 treatments accelerates. Science 367: 1412-1413, 2020.

4. Zhou P, Yang XL, Wang XG, Hu B, Zhang L, Zhang W, Si HR, Zhu Y, Li B, Huang CL, et al: A pneumonia outbreak associated with a new coronavirus of probable bat origin. Nature 579: 270-273, 2020.

5. Docea AO, Tsatsakis A, Albulescu D, Cristea O, Zlatian O, Vinceti M, Moschos SA, Tsoukalas D, Goumenou M, Drakoulis N, et al: A new threat from an old enemy: Re-emergence of coronavirus (Review). Int J Mol Med 45: 1631-1643, 2020.

6. Wang D, Hu B, Hu C, Zhu F, Liu X, Zhang J, Wang B, Xiang H, Cheng Z, Xiong Y, et al: Clinical characteristics of 138 hospitalized patients with 2019 novel coronavirus-infected pneumonia in Wuhan, China. JAMA doi: 10.1001/jama.2020.1585, 2020 [Epub ahead of print].

7. Andersen KG, Rambaut A, Lipkin WI, Holmes EC and Garry RF: The proximal origin of SARS-CoV-2. Nat Med 26: 450-452, 2020

8. Sheahan TP, Sims AC, Graham RL, Menachery VD, Gralinski LE, Case JB, Leist SR, Pyrc K, Feng JY, Trantcheva I, et al: Broadspectrum antiviral GS-5734 inhibits both epidemic and zoonotic coronaviruses. Sci Transl Med 9: pii: eaal3653, 2017.

9. Wang M, Cao R, Zhang L, Yang X, Liu J, Xu M, Shi Z, Hu Z, Zhong W and Xiao G: Remdesivir and chloroquine effectively inhibit the recently emerged novel coronavirus (2019-nCoV) in vitro. Cell Res 30: 269-271, 2020

10. Agostini ML, Andres EL, Sims AC, Graham RL, Sheahan TP, Lu X, Smith EC, Case JB, Feng JY, Jordan R, et al: Coronavirus susceptibility to the antiviral remdesivir (GS-5734) is mediated by the viral polymerase and the proofreading exoribonuclease. mBio 9: pii: e00221-18, 2018.

11. Grein J, Ohmagari N, Shin D, Diaz G, Asperges E, Castagna A, Feldt T, Green G, Green ML, Lescure FX, et al: Compassionate use of remdesivir for patients with severe Covid-19. N Engl J Med doi: 10.1056/NEJMoa2007016, 2020 [Epub ahead of print].

12. Hoffmann M, Kleine-Weber H, Schroeder S, Krüger N, Herrler T, Erichsen S, Schiergens TS, Herrler G, Wu NH, Nitsche A, et al: SARS-CoV-2 cell entry depends on ACE2 and TMPRSS2 and is blocked by a clinically proven protease inhibitor. Cell 181: 271-280.e8, 2020.

13. Rainsford KD, Parke AL, Clifford-Rashotte M and Kean WF: Therapy and pharmacological properties of hydroxychloroquine and chloroquine in treatment of systemic lupus erythematosus, rheumatoid arthritis and related diseases. Inflammopharmacology 23: 231-269, 2015.

14. Chen Z, Hu J, Zhang Z, Jiang S, Han S, Yan D, Zhuang R, Hu B and Zhang Z: Efficacy of hydroxychloroquine in patients with COVID-19: Results of a randomized clinical trial. medRxiv doi 2020.03.22.20040758, 2020.

15. Gautret P, Lagier JC, Parola P, Hoang VT, Meddeb L, Mailhe M, Doudier B, Courjon J, Giordanengo V, Vieira VE, et al: Hydroxychloroquine and azithromycin as a treatment of COVID-19: Results of an open-label non-randomized clinical trial. Int $\mathrm{J}$ Antimicrob Agents doi: 10.1016/j.ijantimicag.2020.105949, 2020 [Epub ahead of print].

16. Sheahan TP, Sims AC, Leist SR, Schäfer A, Won J, Brown AJ, Montgomery SA, Hogg A, Babusis D, Clarke MO, et al: Comparative therapeutic efficacy of remdesivir and combination lopinavir, ritonavir, and interferon beta against MERS-CoV. Nat Commun 11: 222, 2020.

17. Baden LR and Rubin EJ: Covid-19 - The search for effective therapy. N Engl J Med doi: 10.1056/NEJMe2005477, 2020 [Epub ahead of print].
18. Cao B, Wang Y, Wen D, Liu W, Wang J, Fan G, Ruan L, Song B, Cai Y, Wei M, et al: A trial of lopinavir-ritonavir in adults hospitalized with severe Covid-19. N Engl J Med doi: 10.1056/ NEJMoa2001282, 2020 [Epub ahead of print].

19. Dong L, Hu S and Gao J: Discovering drugs to treat coronavirus disease 2019 (COVID-19). Drug Discov Ther 14: 58-60, 2020.

20. Chen C, Zhang Y, Huang J, Yin P, Cheng Z, Wu J, Chen S, Zhang Y, Chen B, Lu M, et al: Favipiravir versus arbidol for COVID-19: a randomized clinical trial. medRxiv doi: 2020.03.17.20037432, 2020.

21. ClinicalTrials.gov. Various combination of protease inhibitors, oseltamivir, favipiravir, and hydroxychloroquine for treatment of COVID-19: a randomized control trial (THDMS-COVID-19). https://clinicaltrials.gov/ct2/show/NCT04303299, 2020.

22. ClinicalTrials.gov. Favipiravir combined with tocilizumab in the treatment of corona virus disease. https://clinicaltrials.gov/ct2/ show/NCT04310228, 2020.

23. Newswire PR: Sihuan pharmaceutical announces clinical research of favipiravir, co-developed with the Academy of Military Medical Sciences of the People's Liberation Army, has commenced. Sihuan Pharmaceutical Holdings Group Ltd, 2020. https:// en.prnasia.com/releases/apac/sihuan-pharmaceutical-announcesclinical-research-of-favipiravir-co-developed-with-the-academyof-military-medical-sciences-of-the-people-s-liberation-armyhas-commenced-273880.shtml

24. Sheahan TP, Sims AC, Zhou S, Graham RL, Pruijssers AJ, Agostini ML, Leist SR, Schäfer A, Dinnon KH III, Stevens LJ, et al: An orally bioavailable broad-spectrum antiviral inhibits SARS-CoV-2 in human airway epithelial cell cultures and multiple coronaviruses in mice. Sci Transl Med pii: eabb5883, 2020.

25. Mehta P, McAuley DF, Brown M, Sanchez E, Tattersall RS, Manson JJ; HLH Across Speciality Collaboration, UK: COVID-19: consider cytokine storm syndromes and immunosuppression. Lancet 395: 1033-1034, 2020.

26. Ritchie AI and Singanayagam A: Immunosuppression for hyperinflammation in COVID-19: a double-edged sword? Lancet 395: $1111,2020$.

27. Alhazzani W, Møller MH, Arabi YM, Loeb M, Gong MN, Fan E, Oczkowski S, Levy MM, Derde L, Dzierba A, et al: Surviving sepsis campaign: guidelines on the management of critically ill adults with coronavirus disease 2019 (COVID-19). Crit Care Med doi: 10.1097/CCM.0000000000004363, 2020 [Epub ahead of print].

28. Poston JT, Patel BK and Davis AM: Management of critically ill adults with COVID-19. JAMA doi: 10.1001/jama.2020.4914, 2020 [Epub ahead of print].

29. Ferioli M, Cisternino C, Leo V, Pisani L, Palange P and Nava S: Protecting healthcare workers from SARS-CoV-2 infection: practical indications. Eur Respir Rev 29: pii: 200068, 2020.

30. Molina JM, Delaugerre C, Le Goff J, Mela-Lima B, Ponscarme D, Goldwirt L and De Castro N: No evidence of rapid antiviral clearance or clinical benefit with the combination of hydroxychloroquine and azithromycin in patients with severe COVID-19 infection. Med Mal Infect pii: S0399-077X(20)30085-8, 2020.

31. Taccone FS, Gorham J and Vincent JL: Hydroxychloroquine in the management of critically ill patients with COVID-19: the need for an evidence base. Lancet Respir Med pii: S22132600(20)30172-7, 2020.

32. Kaly L and Rosner I: Tocilizumab - a novel therapy for non-organspecific autoimmune diseases. Best Pract Res Clin Rheumatol 26: 157-165, 2012.

33. Xu X,Han M,Li T, Sun W, Wang D, Fu B,Zhou Y,Zheng X, Yang Y, Li X, et al: Effective treatment of severe COVID-19 patients with tocilizumab. ChinaXiv preprint, 2020. chinaXiv:202003.00026v1

34. ClinicalTrials.gov. A study to evaluate the safety and efficacy of tocilizumab in patients with severe COVID-19 pneumonia (COVACTA). https://clinicaltrials.gov/ct2/show/NCT04320615, 2020.

35. Atluri S, Manchikanti L and Hirsch JA: Expanded umbilical cord mesenchymal stem cells (UC-MSCs) as a therapeutic strategy in mnaging critically III COVID-19 patients: the case for compassionate use. Pain Physician E71-E83, 2020.

36. Leng Z, Zhu R, Hou W, Feng Y, Yang Y, Han Q, Shan G, Meng F, Du D, Wang S, et al: Transplantation of ACE2(-) mesenchymal stem cells improves the outcome of ptients with COVID-19 pneumonia. Aging Dis 11: 216-228, 2020.

This work is licensed under a Creative Commons Attribution-NonCommercial-NoDerivatives 4.0 International (CC BY-NC-ND 4.0) License. 